\title{
Electron Probe Microanalysis Study on an Unusual Chernobyl "Hot" Particle
}

\author{
Philipp Pöml ${ }^{1}$, Boris Burakov ${ }^{2}$ and Thorsten Geisler ${ }^{3}$ \\ 1. European Commission, Joint Research Centre, Institute for Transuranium Elements, P.O. Box 2340, \\ 76125 Karlsruhe, Germany \\ 2. V.G. Khlopin Radium Institute, 28, 2-nd Murinskiy ave., St. Petersburg, 194021, Russia \\ 3. Steinmann Institut für Geologie, Mineralogie und Paläontologie, University of Bonn, Poppelsdorfer \\ Schloss, 53115 Bonn, Germany
}

Understanding the behaviour of nuclear fuel under severe accident conditions is critical to the assessment of the safety of nuclear power plants during such events. On April 26 1986, an explosion occurred at the $4^{\text {th }}$ unit of the Chernobyl nuclear power plant (NPP), located near the ctity of Pripyat in the Ukraine. The reactor core was destroyed and large amounts of radionuclides were released to the environment. As a result of the accident, solid-phase highly radioactive particles (so-called "hot" particles) were ejected from the reactor core and were dispersed into the environment. Most "hot" particles consist of $\mathrm{UO}_{\mathrm{x}}$ (i.e., dispersed fragments of fuel), but some of them contain various amounts of $\mathrm{Zr}$ and represent different solid-solutions in the system $\mathrm{UO}_{2}-\mathrm{ZrO}_{2}$. This leads to the conclusion that high-temperature $\left(>2600{ }^{\circ} \mathrm{C}\right)$ interaction between fuel $\left(\mathrm{UO}_{\mathrm{x}}\right)$ and cladding (metallic $\mathrm{Zr}$ with 1 wt. \% $\mathrm{Nb})$ took place in local parts of the reactor core before the explosion.

In this paper we present electron probe micro-analysis (EPMA) data on a very rare "hot" particle separated from a soil sample collected $6 \mathrm{~km}$ west of the Chernobyl nuclear power plant (Fig. 1). In contrast to the vast majority, this particle contains mainly metallic zirconium and locally metallic uranium. The occurrence of metallic "hot" particles is unusual, which makes this a very rare specimen. In order to study the local chemical composition of the "hot" particle we conducted EPMA point analysis and quantitative X-ray mapping on the sample.

Fig. 1 shows secondary electron (SE) and backscatter electron (BSE) images of the "hot" particle. The white rectangle in the SE image marks the location of the BSE image and the quantitative element maps (Fig. 2). The particle is about $150 \mu \mathrm{m}$ in diameter. The BSE image shows a mid-grey matrix, with some areas of a darker BSE contrast. Some spots containing heavier elements are visible as a white BSE contrast. Fig. 2 reveals that the matrix consists of metallic, slightly oxidised Zr. The areas with darker BSE contrast correspond to areas that are slightly more oxidised. The $\mathrm{Nb}$ and $\mathrm{U}$ maps show that the phase with a white BSE contrast consists of metallic $\mathrm{U}$ and $\mathrm{Nb}$.

The EPMA analysis confirms that the "hot" particle consists indeed of a metallic Zr matrix that is, however, slightly oxidised. The $\mathrm{U}$ and $\mathrm{Nb}$ in this sample form a metallic admixture within the matrix. This proves that high-temperature interaction of nuclear fuel and cladding before the explosion lasted for only a very short time (probably much less than 1 second) and no water (steam) was involved in the process of core destruction, at least locally. 

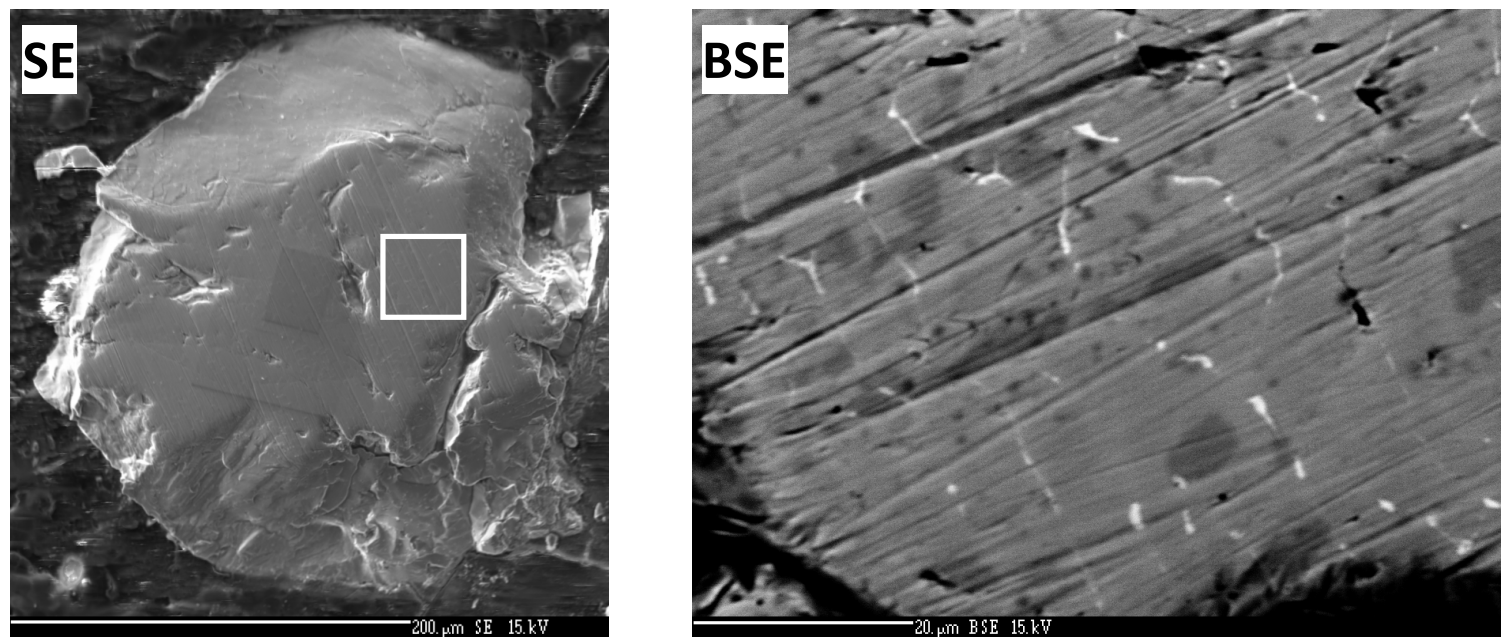

Figure 1. Secondary electron (SE) and backscatter electron (BSE) images of the "hot" particle. The square in the SE image marks the location of the BSE image and the element maps shown in Fig. 2.
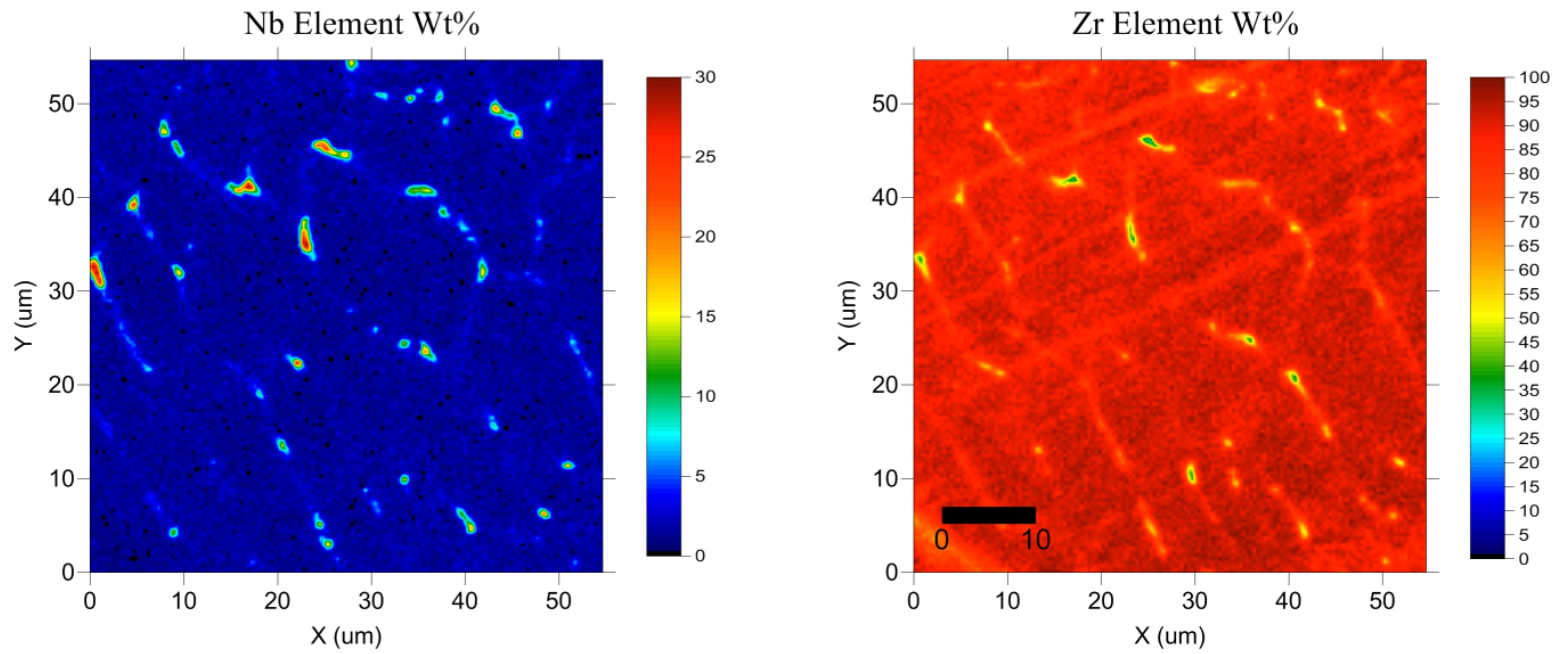

$\mathrm{U}$ Element $\mathrm{Wt} \%$
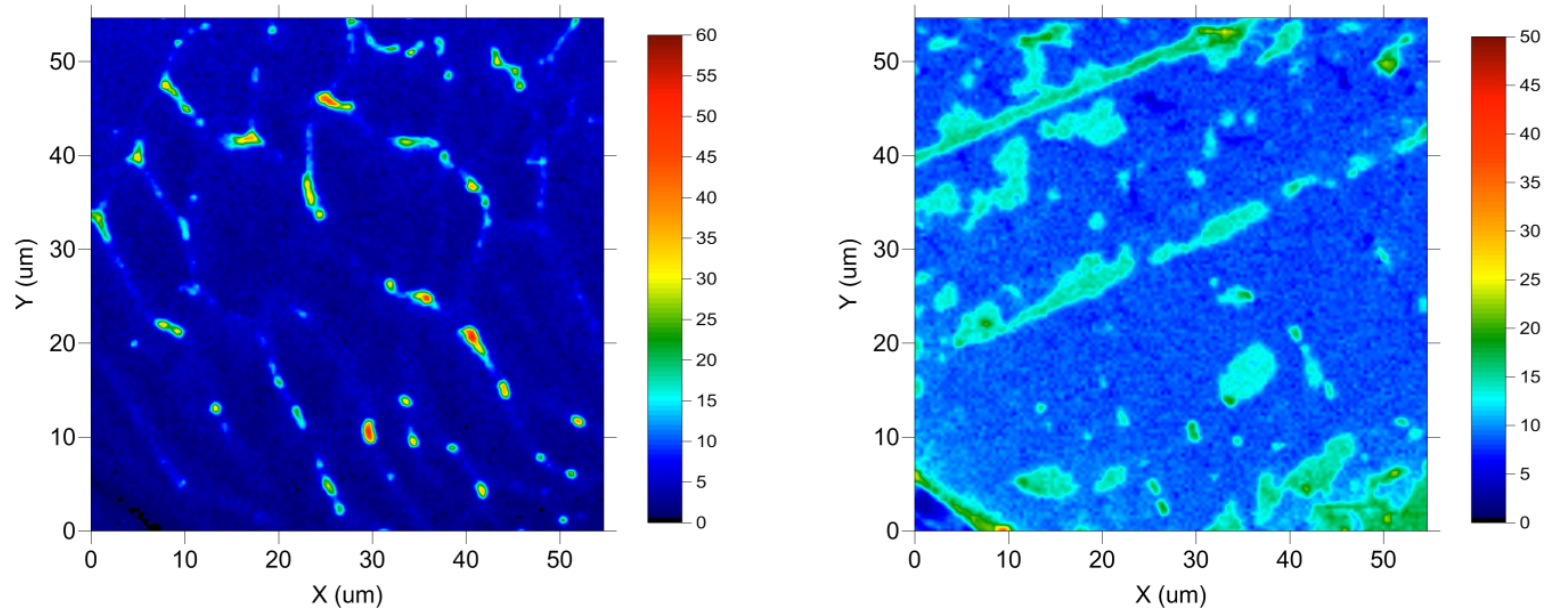

Figure 2. Quantitative element distribution maps for $\mathrm{Nb}, \mathrm{Zr}, \mathrm{U}$, and $\mathrm{O}$. The maps show that $\mathrm{U}$ and $\mathrm{Nb}$ accumulate in one phase (white contrast in Fig $1 \mathrm{BSE}$ ) within a $\mathrm{Zr}$ matrix. The areas of the matrix having a darker BSE contrast (Fig. 1) correspond to areas with a higher O concentration. 